\title{
Interrelationships of Glucose and Insulin Uptake by Muscle of Normal and Diabetic Man
}

\author{
Evidence of a Difference in Metabolism of Endogenous and Exogenous Insulin \\ N. Kalant, T. Leibovici, I. Rohan, and S. Ozaki \\ Lady Davis Institute for Medical Research, Jewish General Hospital, Montreal, Quebec, Canada
}

\begin{abstract}
Summary. A forearm perfusion technique was used to study glucose and insulin uptake by muscle. In normal subjects at glycaemic levels above $130 \mathrm{mg} /$ $100 \mathrm{ml}$, glucose uptake was independent of glucose concentration; it was directly related to insulin concentration but not to insulin uptake. In non-obese maturity-onset diabetic subjects, glucose uptake was dependent on glucose concentration and insulin uptake, but not on insulin concentration. In both groups there was a strong correlation between insulin concentration and insulin uptake; diabetics had a normal insulin uptake in relation to concentration. For a given change in insulin concentration the increase in glucose uptake was as great in diabetics as in controls, but the effect of insulin was mediated through a mechanism involving its uptake. Thus in the non-obese maturity-onset diabetic, forearm muscle is not insulin resistant. The apparent uptake of insulin measured by a radioimmunoassay in relation to its arterial concentration was lower and more variable for heterologous than for endogenous insulin. With a receptor assay the venous insulin concentrations were lower than with the immunoassay and differences in uptake between endogenous and exogenous insulin disappeared. It is concluded that in muscle exogenous insulin was less severely degraded than endogenous insulin.
\end{abstract}

Key words: Glucose concentration, glucose uptake, insulin concentration, insulin uptake, muscle, diabetes, radioreceptor assay.

A number of studies of the perfused forearm have demonstrated an insulin-stimulated increase in glucose uptake by muscle in normal subjects [1-5].
However there is little information on the tissue uptake of insulin and the possible relationship of this to glucose utilization. Butterfield, Garratt and Whichelow [6] measured the tissue uptake of glucose and insulin following intra-arterial injection of ${ }^{131} \mathrm{I}-$ insulin; they found that insulin uptake was directly related to plasma insulin concentration and that glucose uptake was linearly related to insulin uptake. Since this was an acute study in a non-steady state, the "uptake" largely reflected movement into the extravascular space rather than cellular uptake or utilization. Rasio et al. [7] subsequently studied the steady state response to a prolonged (1 hour) infusion of insulin; while again observing a linear relationship between plasma insulin concentration and insulin uptake, they did not find a relationship between cell glucose uptake and either insulin uptake or insulin concentration. These authors also found that intra-arterial injection of glucose led to a fall in arterial insulin concentration. Because of these unexpected findings and because of unusually high and variable blood flow in the subjects studied, we have re-examined the steady-state relationships between glucose and insulin uptake, in normal and diabetic subjects.

\section{Materials and Methods}

Studies were made on 9 non-diabetic and 11 diabetic men. A detailed explanation of the goals and procedures of the experiment was given and consent obtained. The non-diabetics were healthy volunteers, aged 40 to 73 (mean \pm s. e. $\mathrm{m}$. $=54 \pm 5$ ); they had no family history of diabetes or other metabolic disease and took no medications. Standard glucose tolerance tests performed in 6 subjects were normal. Body weight was $102 \pm 3 \%$ of ideal (range 94-107). Preparation of the subjects was as previously described [8]; a diet containing 250-300 g of carbohydrate was taken for 3 days preceding the experimental procedure, and no food was taken for $14-15 \mathrm{~h}$ immediately preceding the study. Diabetic subjects 
Table 1. Clinical information on diabetic subjects

\begin{tabular}{|c|c|c|c|c|c|c|}
\hline 氋 & $\underset{8}{8}$ & 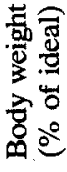 & 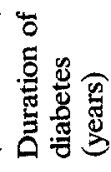 & $\begin{array}{l}\text { Hypoglycaemi } \\
\text { (daily dose) }\end{array}$ & ic agent & $\begin{array}{l}\text { Other } \\
\text { medication }\end{array}$ \\
\hline 1 & 59 & 103 & 4 & - & & Amytriptyline \\
\hline 2 & 45 & 107 & Recent & - & & Digoxin \\
\hline 3 & 63 & 98 & 9 & Chlorpropamide & $(200 \mathrm{mg})$ & - \\
\hline 4 & 63 & 105 & 2 & Chlorpropamide & $(100 \mathrm{mg})$ & - \\
\hline 5 & 52 & 106 & 10 & Tolbutamide & $(1 \mathrm{~g})$ & - \\
\hline 6 & 68 & 97 & 5 & - & & - \\
\hline 7 & 63 & 103 & 9 & Chlorpropamide & (200 mg) & - \\
\hline 8 & 40 & 103 & 2 & - & & - \\
\hline 9 & 67 & 97 & 16 & Tolbutamide & $(0.5 \mathrm{~g})$ & - \\
\hline 10 & 69 & 106 & 16 & - & & - \\
\hline 11 & 57 & 98 & 8 & - & & - \\
\hline
\end{tabular}

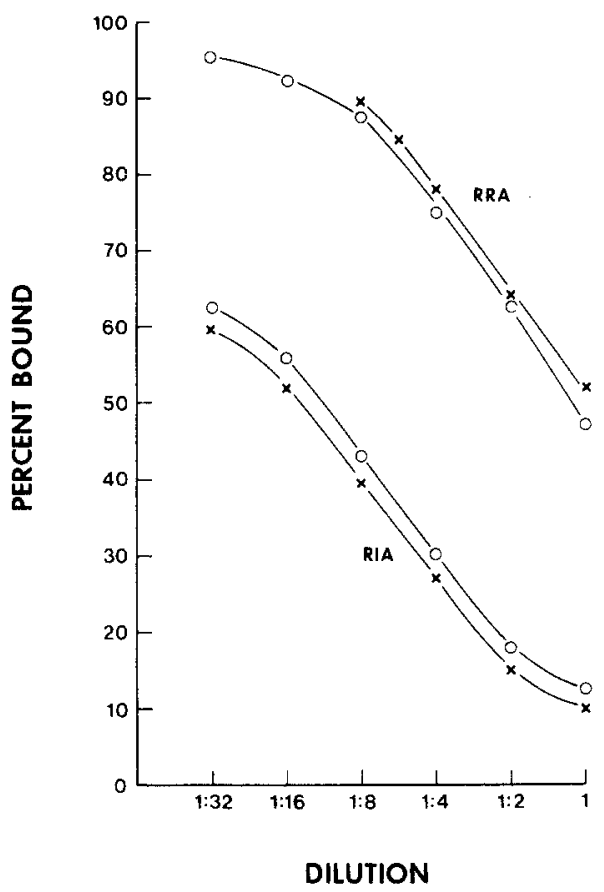

Fig. 1. Dilution curves of monocomponent insulin added to serum and assayed by immunoassay (RIA) and receptor assay (RRA). $\bigcirc-0$, Standard curve. $\times \longrightarrow \times$, Dilution curve of serum containing $30 \mu \mathrm{U} / \mathrm{ml}$ of endogenous insulin and $100 \mu \mathrm{U} / \mathrm{ml}$ of monocomponent insulin

were all of the maturity-onset type; they were in good health apart from the diabetes and were leading normally active lives. Pertinent information is shown in Table 1. All were under treatment with diet, alone or with an oral hypoglycaemic agent; the diet was liberal $(225-300 \mathrm{~g})$ in carbohydrate and was not altered prior to the experiment. None had previously received insulin. The last dose of hypoglycaemic drug was taken on the morning prior to the procedure. Body weights of all subjects were within $10 \%$ of ideal.
The technique and validity of the forearm perfusion procedure have been described previously [8]. Briefly, blood is sampled from a deep vein draining the forearm muscle and from a vein on the dorsum of the contralateral hand which was warmed to increase blood flow so that the venous blood was "arterialized" [9]; blood flow was measured by strain-gauge plethysmography [10]. Infusions of glucose and insulin were introduced into an antecubital vein.

Subjects were studied in the basal state and during steady-state periods of hyperglycaemia produced by glucose infusions. Following introduction of the indwelling needles for blood sampling, arterialized blood glucose was measured at $5 \mathrm{~min}$ intervals for the remainder of the experiment. After a 30-60 min rest period to ensure a steady state, blood sampling and blood flow measurements were made. A new glycaemic steady state was then established by an intravenous pulse $(0.125 \mathrm{~g} / \mathrm{kg})$ and subsequent infusion of $50 \mathrm{~g} / 100 \mathrm{ml}$ glucose solution. A glucose clamp procedure was used to maintain constancy of the plasma glucose concentration [8]. When the plasma glucose had been constant for 1 hour at the new level sampling and flow measurements were made. The rate of infusion was varied from 1 subject to another to achieve a range of plasma glucose concentration and thus of endogenous plasma insulin concentration. In 3 non-diabetic and 2 diabetic subjects a second level of hyperglycaemia was established by a further pulse of glucose and a faster infusion of glucose solution; stabilization at the new level for $1 \mathrm{~h}$ was then followed by sampling and flow measurements as before. One subject in each group was studied only in the basal state while observations in the basal state were omitted for 2 non-diabetics and 3 diabetics. Two of the nor$\mathrm{mal}$ and six of the diabetic subjects were given intravenous infusions of monocomponent insulin $(0.75 \mathrm{mU} / \mathrm{kg} / \mathrm{min})$ with the glucose infusion to extend the range of plasma insulin concentrations during the hyperglycaemic periods.

During each period (basal and hyperglycaemic) sampling of arterialized and deep venous blood and measurements of blood flow were made 3-4 times at 15 min intervals. Blood flow was first measured 12-15 times over a 5-min interval; immediately following this, while the wrist cuff was still inflated, blood was drawn simultaneously from the deep vein and the arterialized vein into heparinized tubes, for subsequent measurement of glucose and insulin. Glucose uptake and insulin uptake were calculated for each sampling interval; the mean concentration and uptake values for each steady-state period were used in subsequent statistical analyses.

Plasma glucose was measured with an oxygen electrode glucose analyzer (Beckman Instruments) at the bedside during the course of the experiment and the result was subsequently verified by measurement in the laboratory. Plasma insulin was measured by radioimmunoassay (RIA) using a charcoal separation of unbound insulin [11] and in some experiments by a radioreceptor assay (RRA) as well [12]; the characteristics of the two assays were (for the RIA and RRA respectively): sensitivity, for standard insulin, $0.35 \mu \mathrm{U} / \mathrm{ml}$ and $0.5 \mu \mathrm{U} / \mathrm{ml}$; sensitivity for plasma insulin, $0.5 \mu \mathrm{U} /$ $\mathrm{ml}$ and $0.7 \mu \mathrm{U} / \mathrm{ml}$; precision $\pm 0.3 \mu \mathrm{U}$ and $\pm 0.4 \mu \mathrm{U}$ at $5 \mu \mathrm{U} / \mathrm{ml}$, \pm $1.9 \mu \mathrm{U}$ and $\pm 1.6 \mu \mathrm{U}$ at $25 \mu \mathrm{U} / \mathrm{ml}, \pm 2.3 \mu \mathrm{U}$ and $\pm 1.8 \mu \mathrm{U} / \mathrm{ml}$ at $40 \mu \mathrm{U} / \mathrm{ml}$; between-assay coefficient of variation, $6.1 \%$ and $5.7 \%$. Dilution-recovery curves of monocomponent insulin added to whole serum were indistinguishable from the standard curve in both assays (Fig. 1). The haematocrit was measured on all samples to exclude the possibility of dilution by the saline solutions used for washing out the venous catheters.

The hypothesis tested during analysis of the data was that arterial glucose concentration determines arterial insulin concentration which in turn determines insulin uptake by muscle cells and that both glucose concentration and insulin uptake control glucose uptake. Results were analyzed by the methods of multiple regression [13] and partial correlation [14]. 


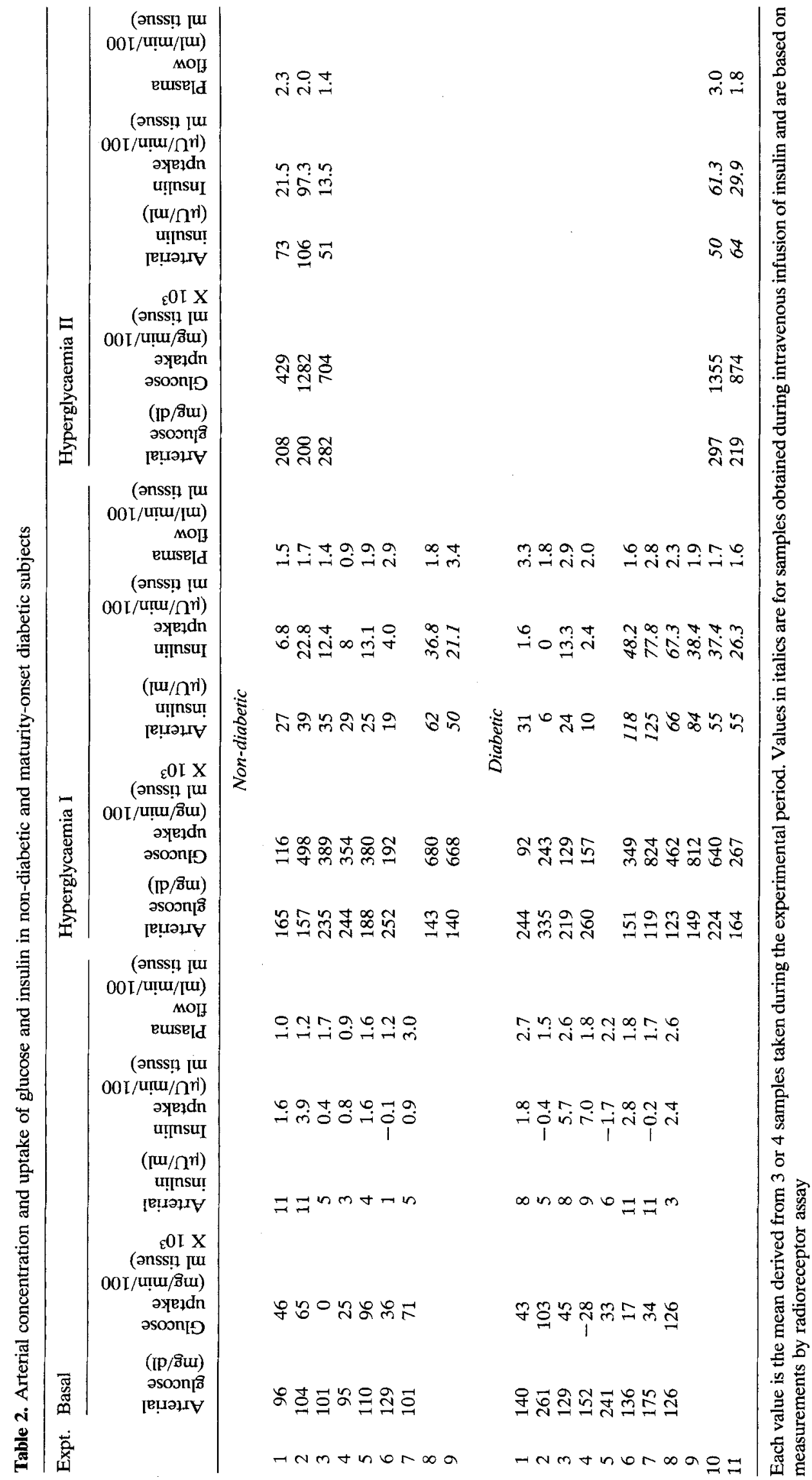



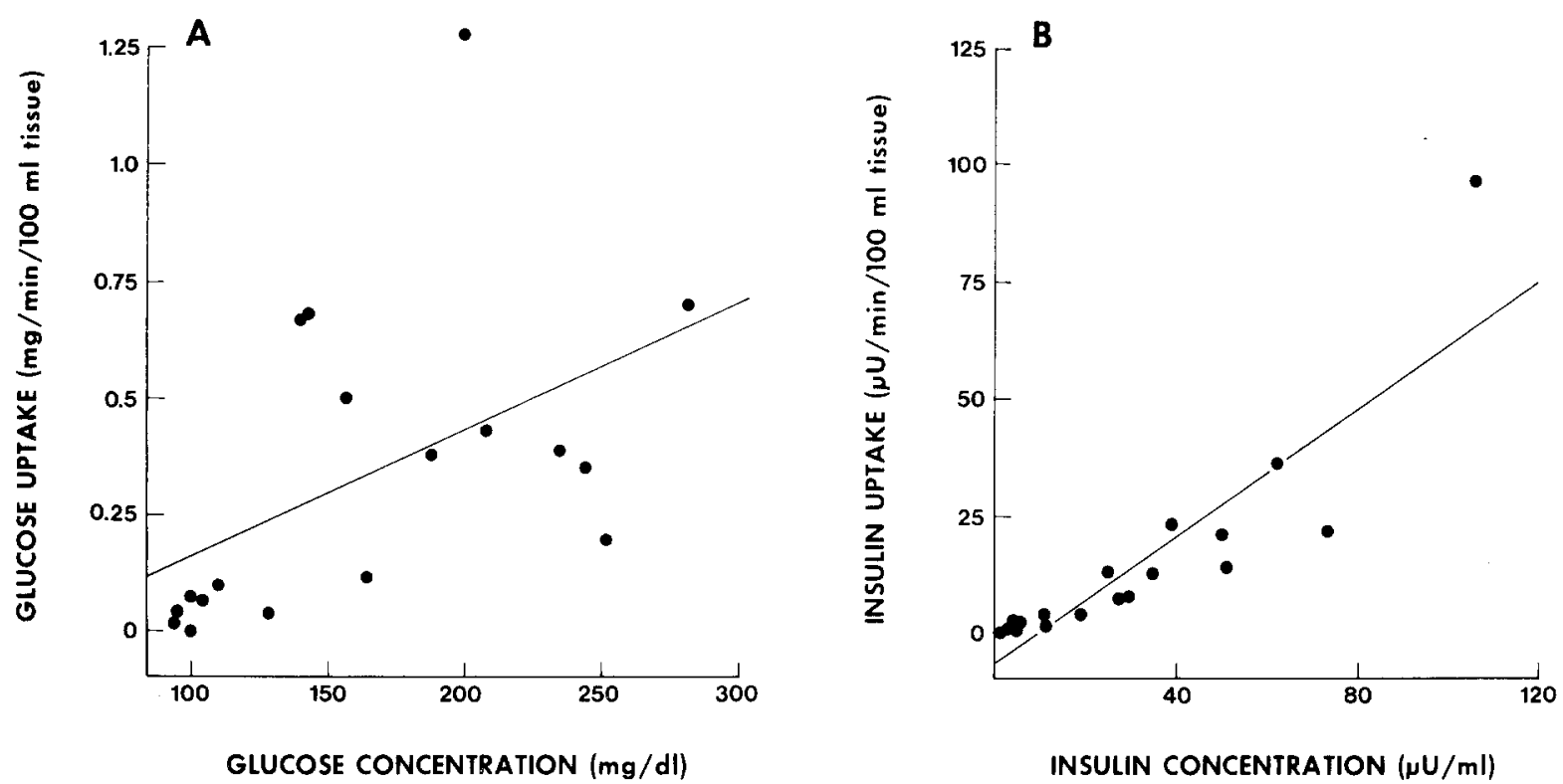

Fig. 2. A Relationship of glucose uptake to arterial glucose concentration in non-diabetic subjects. This demonstrates the correlation before controlling for the influence of insulin concentration on uptake. Regression equation: $Y=-0.126+0.0028 \mathrm{X}$. Correlation coefficient, $r$ $=0.51$. B Relationship of insulin uptake to arterial insulin concentration in non-diabetic subjects. When radioreceptor assay values are used for the 2 data points obtained during insulin infusion, the regression equation is: $Y=-7.22+0.69 X$ and correlation coefficient, $r=$ 0.86 . When immunoassay results are used for all data the regression equation is: $Y=-7.19+0.63 \mathrm{X}$, with a regression coefficient, $\mathrm{r}=$ 0.78

\section{Results}

All individual results are shown in Table 2. For the 20 experiments the glucose concentrations were constant within $\pm 2 \mathrm{mg} / \mathrm{dl}$ of the mean during each period; insulin concentrations were within $\pm 1 \mu \mathrm{U} /$ $\mathrm{ml}$ during the basal periods and within $\pm 2 \mu \mathrm{U} / \mathrm{ml}$ during hyperglycaemia. Plasma flow was constant within $\pm 5 \%$ of the mean. These results are in keeping with those reported previously [8].

\section{Glucose Utilization}

The rate of glucose utilization by the whole body during a steady-state period obtained by glucose infusion was taken as the mean infusion rate for that period; these utilization rates were examined in relation to glucose and insulin concentration. The regression of the utilization rate on the two variables was considerably greater in the non-diabetics: for the normal and diabetic groups respectively, the regression coefficients for glucose utilization on glucose concentration were 0.110 and 0.001 , and for utilization on insulin concentration, 0.468 and 0.004 . The overall difference between the two groups was significant $(\mathrm{P}<0.005)$. Since the average glucose concentrations were similar in the two groups $(201 \pm 14 \mathrm{mg} / \mathrm{dl}$ and $209 \pm 20 \mathrm{mg} / \mathrm{dl}$ for non-diabetic and diabetic groups) an additional estimate of insulin effectiveness was obtained from the ratio, glucose utilization $(\mathrm{mg} / \mathrm{min} / \mathrm{kg}) /$ mean insulin concentration; this averaged $0.18 \pm 0.02$ and $0.10 \pm 0.02$ (mean \pm s.e.m.) for the non diabetic and diabetic subjects, respectively $(\mathrm{P}<0.025)$. These analyses demonstrate that the diabetic subjects showed insulin unresponsiveness as well as decreased glucose tolerance.

\section{Muscle Uptake of Glucose and Insulin}

In the non-diabetics, there was a significant relationship between concentration and uptake for both glucose and insulin (Fig. 2). The relationship between insulin uptake and insulin concentration in the diabetics is seen in Figure $3 \mathrm{~A}$. When immunoassay values were used for samples obtained during insulin infusion, all estimates of uptake fell below the regression line of uptake on concentration of endogenous insulin and some of the uptake values were clearly negative.

Plasma insulin in the samples from the insulin infusion experiments was then measured by the radioreceptor assay, together with 30 randomly selected samples from diabetic and non-diabetic subjects who did not receive an insulin infusion. In the samples from non-insulin infused subjects and in arterialized venous samples from the insulin infused 


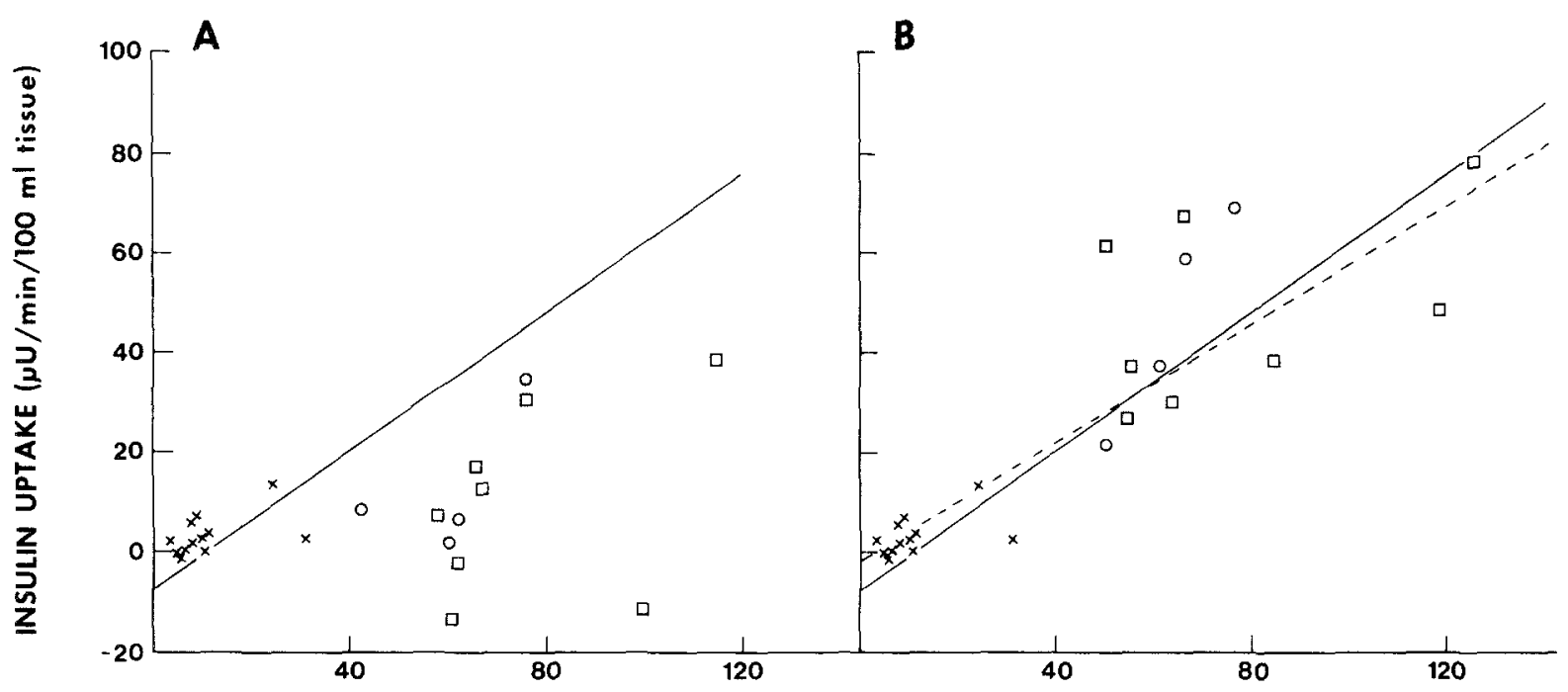

INSULIN CONCENTRATION $(\mu \mathrm{U} / \mathrm{ml})$

Fig. $3 \mathrm{~A}$ and B. Relationship of insulin uptake to arterial concentration for exogenous and endogenous insulins. The solid line is the regression line of uptake on concentration for endogenous insulin in non-diabetic subjects, taken from Fig. $2 \mathrm{~B}$. $\times$, Endogenous insulin in diabetic subjects. $\sqsupset$, Exogenous insulin in diabetics. $\odot$, Exogenous insulin in non-diabetics; two of these are from experiments included in Table 2 while the other two, from younger subjects, are shown here only as additional information. A All measurements by radioimmunoassay. Regression equation for diabetics: $Y=0.67+0.13 \mathrm{X}$. Correlation coefficient, $r=0.35$ ( $P>0.1$ ). B Exogenous insulin measured by radioreceptor assay; broken line is regression line for all diabetic data. Regression equation, $\mathrm{Y}=-0.92+0.59 \mathrm{X}$. Correlation coefficient, $\mathrm{r}=0.88(\mathbf{P}<0.001)$

subjects the receptor assay gave slightly higher values than the immunoassay $(3-4 \mu \mathrm{U} / \mathrm{ml})$; however, in deep venous sera from insulin infused subjects the receptor assay gave distinctly lower values than the immunoassay (mean \pm s.e.m. of difference $=$ $-12 \pm 2 \mu \mathrm{U} / \mathrm{ml}$ ). For both diabetics and non-diabetics estimates of insulin uptake based on the receptor assay results were all higher than those based on immunoassay and much closer to the regression line for the non-diabetic data obtained without insulin infusion (Fig. 3B).

\section{Correlation and Regression Analyses}

For each of the two groups, non-diabetic and diabetic, an analysis was made of the data pooled from all experiments, using the receptor assay values of insulin concentration in those experiments in which an insulin infusion had been given. For the nondiabetic subjects (Table 3 ), the dependence of glucose uptake on glucose concentration was not statistically significant when the influence of insulin concentration was removed. Glucose uptake was strongly dependent on insulin concentration, but not on insulin uptake as seen when the influence of insulin concentration was excluded.Insulin uptake was highly dependent on glucose uptake and on insulin concentration, but the dependence on each of these two factors was greatly diminished by controlling the other. Insulin concentration was positively correlated to glucose concentration, particularly when insulin uptake was controlled.

Partial correlation analysis of data from the diabetics (Table 4) shows two major differences from that of the non-diabetics: (a) the relationship between glucose uptake and glucose concentration was significant even when insulin concentration was controlled; (b) glucose uptake was related to insulin uptake, but not to insulin concentration. As with the normal subjects there was a strong negative correlation between insulin uptake and glucose concentration.

Multiple regression analyses of glucose uptake demonstrated that the influence of glucose concentration was small in both groups of subjects (regression coefficients of 0.001 and 0.002 for non-diabetics and diabetics respectively). In the non-diabetics the only significant determinant of glucose uptake was insulin concentration (regression coefficient $0.006, \mathrm{P}$ $<0.001$ ), while in the diabetics only insulin uptake was effective (regression coefficient 0.013, P $<0.001$ ).

Similar analyses of insulin uptake showed no significant differences between the two groups: for normal and diabetic subjects, respectively, the regression coefficients of insulin uptake on insulin concentration 
Table 3. Partial correlation coefficients for non-diabetic subjects

\begin{tabular}{|c|c|c|c|c|c|}
\hline & \multirow[b]{2}{*}{$\begin{array}{l}\text { Simple } \\
\text { correlation }\end{array}$} & \multicolumn{4}{|c|}{ Partial correlation excluding effect of } \\
\hline & & $\begin{array}{l}\text { Glucose } \\
\text { concentration }\end{array}$ & $\begin{array}{l}\text { Glucose } \\
\text { uptake }\end{array}$ & $\begin{array}{l}\text { Insulin } \\
\text { concentration }\end{array}$ & $\begin{array}{l}\text { Insulin } \\
\text { uptake }\end{array}$ \\
\hline Glucose uptake: glucose concentration & $0.51^{\mathrm{a}}$ & - & - & 0.11 & $0.66^{\mathrm{b}}$ \\
\hline Insulin concentration: glucose concentration ${ }^{\mathrm{d}}$ & $0.51^{\mathrm{a}}$ & - & 0.11 & - & $0.64^{b}$ \\
\hline Insulin uptake: glucose concentration & 0.21 & - & $-0.53^{\mathrm{a}}$ & $-0.5^{a}$ & - \\
\hline Glucose uptake: insulin concentration & $0.93^{c}$ & $0.91^{\mathrm{c}}$ & - & - & $0.73^{c}$ \\
\hline Glucose uptake: insulin uptake & $0.87^{\mathrm{c}}$ & $0.9^{c}$ & - & 0.36 & - \\
\hline Insulin uptake: insulin concentration & $0.86^{\mathrm{c}}$ & $0.89^{c}$ & 0.28 & - & - \\
\hline
\end{tabular}

${ }^{a} \mathrm{P}<0.025 ;$ b $\mathrm{P}<0.01 ;$ c $\mathrm{P}<0.001$

Based on 18 values obtained in 9 experiments, using radioreceptor assay values for insulin measurement in those experiments which incorporated an infusion of insulin

d The administration of exogenous insulin distorts any physiological relationship of these parameters; correlation coefficients are given for completeness only. This artefact does not affect the validity of other relationships.

Table 4. Partial correlation coefficients for diabetic subjects

\begin{tabular}{|c|c|c|c|c|c|}
\hline \multirow[b]{2}{*}{ Parameters } & \multirow[b]{2}{*}{$\begin{array}{l}\text { Simple } \\
\text { correlation }\end{array}$} & \multicolumn{4}{|c|}{ Partial correlation excluding effect of } \\
\hline & & $\begin{array}{l}\text { Glucose } \\
\text { concentration }\end{array}$ & $\begin{array}{l}\text { Glucose } \\
\text { uptake }\end{array}$ & $\begin{array}{l}\text { Insulin } \\
\text { concentration }\end{array}$ & $\begin{array}{l}\text { Insulin } \\
\text { uptake }\end{array}$ \\
\hline Glucose uptake: glucose concentration & 0.17 & - & - & $0.51^{\mathrm{a}}$ & $0.65^{b}$ \\
\hline Insulin concentration: glucose concentration ${ }^{\mathrm{d}}$ & -0.29 & - & $0.55^{\mathrm{a}}$ & - & -0.19 \\
\hline Insulin uptake: glucose concentration & -0.23 & - & $-0.61^{b}$ & 0.05 & - \\
\hline Glucose uptake: insulin concentration & $0.66^{\mathrm{c}}$ & $0.75^{\mathrm{c}}$ & - & - & -0.11 \\
\hline Glucose uptake: insulin uptake & $0.79^{c}$ & $0.87^{\mathrm{c}}$ & - & $0.58^{\mathrm{b}}$ & - \\
\hline Insulin uptake: insulin concentration & $0.88^{\mathrm{c}}$ & $0.87^{\mathrm{c}}$ & $0.77^{\mathrm{c}}$ & - & - \\
\hline
\end{tabular}

${ }^{\text {a }} \mathrm{P}<0.025 ;$ b $\mathrm{P}<0.01 ;{ }^{c} \mathrm{P}<0.001$

Based on 20 values obtained in 11 experiments, using radioreceptor assay values for insulin measurement in those experiments which incorporated an infusion of insulin

d See footnote to Table 3

alone were 0.312 and 0.416 , while for insulin uptake on glucose uptake alone they were 34.66 and 26.27. However, while no interaction between the insulin concentration and glucose uptake was evident in the diabetics, there was strong interaction in the normals ( $F$ for interaction significant at 0.001 ).

From the regressions of insulin uptake and glucose uptake on insulin concentration it can be calculated that unit change in insulin concentration produced changes in glucose uptake of $0.006 \mathrm{mg} / \mathrm{min} /$ $100 \mathrm{ml}$ in the normal subjects and of $0.0054 \mathrm{mg} / \mathrm{min} /$ $100 \mathrm{ml}$ in diabetics.

\section{Discussion}

Several authors have previously examined the interrelationships of glucose and insulin in the perfused forearm, particularly with regard to the role of glucose concentration and of insulin concentration as determinants of glucose utilization $[1-7,15]$. Though based on the Fick principle for calculation of glucose uptake, a number of the earlier studies $[2,6,14]$ did not meet the criteria for a steady state, which is essential for valid application of the Fick principle. In addition insulin was sometimes given as a single pulse or as an infusion in an amount sufficient to raise the plasma concentration to unphysiologically high levels $[1,2]$. More recently, Christensen and Ørskov [16] on the basis of experiments in which the glucose concentration was fairly constant, concluded that there was no significant correlation between arterial glucose concentration and glucose uptake in the nondiabetic. Our results, based on the partial correlation after removing the effect of insulin concentration, are in agreement with this. However, in diabetics we found a small but significant dependence of glucose uptake on glucose concentration.

It is possible that in the normal subjects the effect of glucose concentration on uptake was already maximal at levels of glycaemia above approximately $130 \mathrm{mg} / 100 \mathrm{ml}$ (i. e. the lowest levels obtained with 
the glucose infusion) while in the diabetics it was not yet maximal even at much higher glucose concentrations. This is compatible with a defect in glucose transport independent of insulin stimulation.

The role of insulin in controlling glucose uptake is more controversial. Zierler and Rabinowitz [17] and Rasio et al. [7] found no effect on glucose uptake of an infusion which increased the arterial insulin concentration up to about $65 \mu \mathrm{U} / \mathrm{ml}$, though a definite effect was noted with an infusion rate 10 times greater [17]. On the other hand a linear relationship between glucose uptake and insulin concentration in the physiological range has been reported by Fineberg and Merimee [5] and by Christensen and Ørskov [16]. In the present work, in the non-diabetics there was a strong relationship between glucose uptake and insulin concentration, independent of insulin uptake, but any correlation between glucose uptake and insulin uptake was greatly diminished by controlling insulin concentration. This suggests that glucose uptake and insulin uptake are independently related to insulin concentration and that the action of insulin on glucose transport is not dependent on insulin metabolism.

The converse situation obtained in the diabetics: glucose uptake was not related to insulin concentration, but was very strongly dependent on insulin uptake. It is assumed that uptake of insulin involves binding to receptor, followed by degradation; these two processes are separate [18]. It is probable that binding equilibrium is reached quickly under steady state conditions in vivo; continued removal of insulin (uptake) is therefore due to degradation. Our results suggest that normally the action of insulin on glucose transport is related directly to the amount of insulin bound at equilibrium and thus to the extracellular insulin concentration, while in the diabetics a new mechanism links degradation to the glucose transport process: there is no indication from the present work of the nature of this link.

Current concepts of responsiveness to insulin are based on quantitative relationships between insulin concentration and glucose concentration or utilization. It is evident that in the diabetic subjects the increase in glucose uptake produced by a unit increase in insulin concentration is as great as in the non-diabetics, even though the effect is mediated by uptake of insulin. Thus the responsiveness of muscle to insulin is normal despite a decrease in whole body responsiveness. This suggests that other tissues, particularly liver and adipose tissue, may be responsible for the insulin unresponsiveness.

It has recently been reported that sulphonylurea treatment leads to increases in insulin responsiveness and in the insulin binding capacity of isolated liver plasma membrane [18]; it is therefore possible that the normal insulin uptake and the normal stimulation of glucose uptake in the muscle of the diabetics were the result of prior sulphonylurea therapy. This seems unlikely for serveral reasons: (a) the subjects continued to show decreased whole body responsiveness to insulin, (b) the uptake of insulin in relation to insulin concentration was the same for the subjects treated with sulphonylureas as for those treated by diet alone (data points for the two groups of subjects are randomly distributed in Fig. 3 B) and (c) an increase in insulin binding capacity to normal would not explain the altered relationship between insulin uptake and glucose uptake.

The significance of the finding in both normal and diabetic subjects of a high, negative correlation between glucose concentration and insulin uptake is not clear. There may be an additional factor associated with the high plasma glucose concentration which inhibits insulin uptake; perhaps catecholamines may play such a role.

An unexpected finding in the subjects receiving insulin infusions was the low and variable insulin uptake in comparison to that seen at comparable plasma concentrations of endogenous insulin. It appeared therefore that the metabolism of exogenous insulin was different from that of endogenous insulin. The results obtained with the radioreceptor assay for insulin confirm this. Mild alteration of the insulin molecule leads to loss of ability to bind to receptor without altering immunoreactivity; further degradation leads to loss of immunoreactivity as well [19]. Evidently, in vivo all endogenous insulin is degraded to the point where it is no longer immunoreactive, while part of the exogenous insulin is less severely degraded and retains immunoreactivity. This would lead to an erroneously low estimate of $\mathrm{AV}$ difference in the concentration of intact insulin and thus of insulin utilization. These results raise the warning that for some studies on insulin metabolism, the fate of exogenous insulin may not reliably mirror the fate of endogenous insulin.

\footnotetext{
Acknowledgements. This work was supported by a grant from the Medical Research Council of Canada.

We are indebted to Dr. W. Eaton for advice and assistance with the statistical analyses.
}

\section{References}

1. Andres, R., Baltzan, M. A., Cader, G., Zierler, K. L.: Effect of insulin on carbohydrate metabolism and on potassium in the forearm of man. J. Clin. Invest. 41, 108-115 (1962)

2. Zampa, G. A., Altilia, F., Bracchetti, D., Geminiani, G. D., Borgatti, E., Odifreddi, M. T.: Studies on peripheral glucose metabolism using the experimental human forearm preparation. Diabetologia 3, 35-46 (1967) 
3. Pozefsky, T., Felig, P., Tobin, J. D., Soeldner, J. S., Cahill, G. F. Jr.: Amino acid balance across tissues of the forearm in post-absorptive man. Effects of insulin at two dose levels. J. Clin. Invest. 48, 2273-2282 (1969)

4. Pozefsky, T., Santis, M. R., Soeldner, J. S., Tancredi, R. C.: Insulin sensitivity of forearm tissues in prediabetic man. $\mathbf{J}$. Clin. Invest. 52, 1608-1615 (1973)

5. Fineberg, S. E., Merimee, T. J.: Effects of comparative perfusions of equimolar, single component insulin and proinsulin in the human forearm. Diabetes 22, 676-686 (1973)

6. Butterfield, W.J.H., Garratt, C. J., Whichelow, M.J.: Peripheral hormone action: Studies on the clearance and effect of [ ${ }^{131}$ I] Iodoinsulin in the peripheral tissues of normal, acromegalic and diabetic subjects. Clin. Sci. Mol. Med. 24, 331-341 (1963)

7. Rasio, E., Whichelow, M. J., Butterfield, W. J. H., Hicks, B. H.: Insulin fixation and glucose uptake by forearm tissues in response to infusions of physiological amounts of insulin in non-diabetic subjects. Diabetologia 8, 244-259 (1972)

8. Kalant, N., Leibovici, T., Rohan, I., McNeill, K.: Effect of exercise on glucose and insulin utilization in the forearm. Metabolism 27, 333-340 (1978)

9. Jackson, R. A., Peters, N., Advani, U., Perry, G., Rogers, J., Brough, W. H., Pilkington, T. R. E.: Forearm glucose uptake during the oral glucose tolerance test in normal subjects. Diabetes 22, 442-458 (1973)

10. Whitney, R. J.: The measurement of volume changes in human limbs. J. Physiol. (Lond.) 121, 1-27 (1953)

11. Albano, J.D. M., Ekins, R.P., Maritz, G., Turner, R.C.: A sensitive precise radioimmunoassay of serum insulin relying on charcoal separation of bound and free hormone moieties. Acta Endocrinol. (Kbh.) 70, 487-509 (1972)

12. Ozaki, S., Kalant, N.: A radioreceptor assay for serum insulin. J. Lab. Clin. Med. 90, 686-699 (1977)
13. Cohen, J.: Multiple regression as a general data-analytic system. Psychol. Bull. 70, 426-443 (1968)

14. Snedecor, G. W., Cochrane, W. G.: Statistical methods, ed. 6, pp. 381-418. Ames: Iowa State University Press 1967

15. Jackson, R. A., Perry, G., Rogers, J., Advani, U., Pilkington, T. R. E.: Relationship between the basal glucose concentration, glucose tolerance and forearm glucose uptake in maturity-onset diabetes. Diabetes 22, 751-761 (1973)

16. Christensen, N. J., Ørskov, H.: The relationship between endogenous serum insulin concentration and glucose uptake in the forearm muscles of nondiabetics. J. Clin. Invest. 47, 1262-1268 (1968)

17. Zierler, K. L., Rabinowitz, D.: Effect of very small concentrations of insulin on forearm metabolism. Persistence of its action on potassium and free fatty acids without its effect on glucose. J. Clin. Invest. 43, 950-962 (1964)

18. Freychet, P., Kahn, R., Roth, J., Neville, D. M. Jr.: Insulin interactions with liver plasma membranes. J. Biol. Chem. 247, 3953-3961 (1972)

19. Feinglos, M. N., Lebovitz, H. E.: Sulfonylureas increase the number of insulin receptors. Nature 276, 184-185 (1978)

Received: September 4, 1978, and in revised form: February 12, 1979

N. Kalant, M. D.

Lady Davis Institute

Jewish General Hospital

3755 Cote Saint Catherine Road

Montreal, Quebec H3T 1E2

Canada 